This item was submitted to Loughborough's Research Repository by the author.

Items in Figshare are protected by copyright, with all rights reserved, unless otherwise indicated.

\title{
Kinetic resolution of secondary allylboronates and their application in the synthesis of homoallylic amines
}

PLEASE CITE THE PUBLISHED VERSION

https://doi.org/10.1002/chem.201804395

\section{PUBLISHER}

(c) Wiley

\section{VERSION}

AM (Accepted Manuscript)

\section{PUBLISHER STATEMENT}

"This is the peer reviewed version of the following article: VILLAR, L. ... et al, 2018. Kinetic resolution of secondary allylboronates and their application in the synthesis of homoallylic amines. Chemistry: a European journal, 24 (61), pp.16262-16265, which has been published in final form at https://doi.org/10.1002/chem.201804395. This article may be used for non-commercial purposes in accordance with Wiley Terms and Conditions for Use of Self-Archived Versions.

\section{LICENCE}

CC BY-NC-ND 4.0

\section{REPOSITORY RECORD}

Villar, Laura, Nick Orlov, Nikolay S. Kondratyev, Uxue Uria, Jose L. Vicario, and Andrei Malkov. 2019. "Kinetic Resolution of Secondary Allylboronates and Their Application in the Synthesis of Homoallylic Amines". figshare. https://hdl.handle.net/2134/34820. 


\title{
Kinetic resolution of secondary allylboronates and their application in the synthesis of homoallylic amines
}

\author{
Laura Villar, ${ }^{[b]}$ Nikolai V. Orlov, ${ }^{[a]}$ Nikolay S. Kondratyev, ${ }^{[a]}$ Uxue Uria, ${ }^{[b]}$ Jose L. Vicario, ${ }^{* b]}$ and \\ Andrei V. Malkov*[a]
}

\begin{abstract}
Highly enantioenriched, chromatographically-stable secondary allylboronates featuring 1,1,2,2-tetraethyl-1,2-ethanediol fragment (Epin) were obtained by kinetic resolution of their racemic mixtures. The Epin group at boron considerably improved stability of allyl boronates allowing them to be readily isolated by chromatography on silica. The resolved reagents were applied in stereoselective synthesis of homoallylic amines with an internal double bond employing unprotected imines formed in situ from aldehydes and ammonia. The reactions proceeded with an excellent transfer of chirality.
\end{abstract}

Chiral amines are powerful pharmacophore groups due to their favourable physico-chemical properties. Homochiral amines and their derivatives belong to the class of strategic building blocks for pharmaceutical, agrochemical and fine chemical development. ${ }^{[1]}$ In this context, chiral homoallylic amines that feature two conveniently placed functional groups, amine and a double bond, occupy an important niche. Allylation of imines can be performed with high enantioselectivity leading to enantioenriched chiral homoallylic amines, ${ }^{[2]}$ where allyl boronates emerged as highly versatile nucleophilic reagents. However, the vast majority of the existing methods are focused on the use of primary achiral reagents 1 that in the presence of a chiral catalyst produce terminal alkenes (Scheme 1a, $\mathbf{1}+\mathbf{2} \rightarrow \mathbf{3}$ ).[3] Synthesis of homologues $E-5$ and $Z-6$ is less straightforward. The shortest approach requires the use of chiral reagents 4 , which competently relay their chirality onto the products (Scheme 1b). However, the geometry of the resulting alkenes relies on the interplay of steric and electronic factors in the TS $\mathbf{A}$ and $\mathbf{B}^{[4,5]}$ leading to the $E$ and $Z$ isomers of the opposite enantiomeric series, thus making control of the geometry a very important factor. The existing synthetic approaches ${ }^{[6]}$ to homochiral boronates 4 can be divided into three main groups: use of chiral auxiliary on boron, ${ }^{[7]}$ use of stoichiometric chiral reagents, ${ }^{[8]}$ and catalytic asymmetric synthesis. ${ }^{[9]}$ It is worth noting that in many instances, boron reagents of type 4 , due to their limited stability, have to be used in situ, without isolation.

[a] Dr. N. V. Orlov; Mr. N. S. Kondratyev; Prof. Dr. A. V. Malkov Department of Chemistry

Loughborough University

Loughborough LE11 3TU, UK

E-mail: a.malkov@lboro.ac.uk

[b] Dr. L. Villar, Dr. U. Uria, Prof. Dr. J. L. Vicario Department of Organic Chemistry II University of the Basque Country (UPV/EHU)

P.O.Box 644, 48080 Bilbao, Spain

E-mail: joseluis.vicario@ehu.es

Supporting information for this article is given via a link at the end of the document.
Herein, we present an alternative practical approach to highly enantioenriched, bench-stable boronates 4 with 1,1,2,2tetraethyl-1,2-ethanediol (Epin) fragment at boron through kinetic resolution of their readily available racemates.

\section{Previous work}

a) linear achiral allyl boron reagents

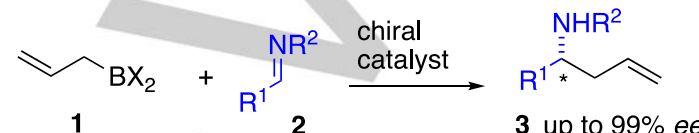

b) branched homochiral allyl boronates

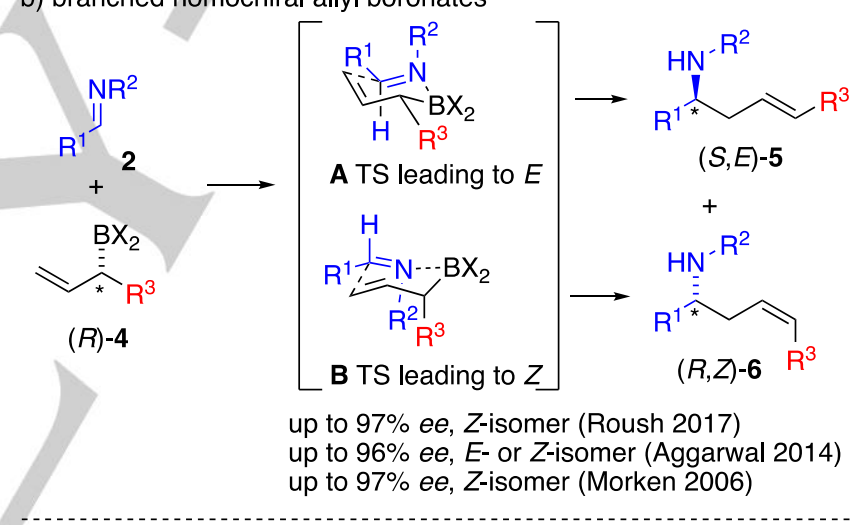

\section{This work}

c) branched racemic allyl boronates

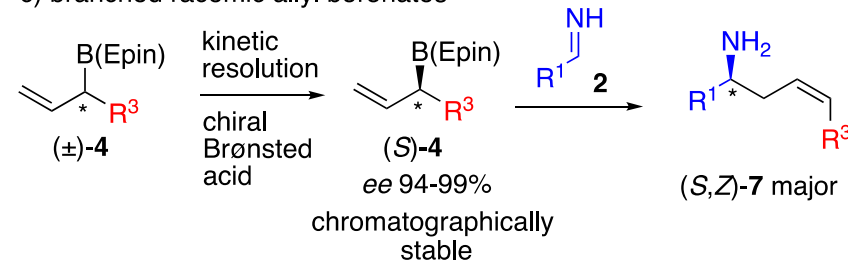

Scheme 1. Asymmetric synthesis of homoallylic amines (Epin $=1,1,2,2$ tetraethyl-1,2-ethanediol).

Importantly, the Epin fragment developed by us $^{[10 a]}$ plays a dual role: (i) it improves the hydrolytic stability of the boronates, thus allowing easy purification by chromatography on silica, and (ii) the increased steric radius of this fragment favors TS B with the $\alpha$-alkyl substituent placed in the pseudo-axial position, which enables stereoselective formation of Z-homoallylic amines 6,7, which cannot be obtained by direct asymmetric methods (Schemes 1b and 1c). All this, coupled with ready access to simple racemic secondary boronates, makes the resolution method a viable alternative to the asymmetric synthesis of these reagents. 
Earlier, ${ }^{[10 a]}$ we reported on the asymmetric allylation of aldehydes with racemic boronates 4 catalyzed by chiral phosphoric acid TRIP (9) that proceeded under the conditions of kinetic resolution furnishing stereoselectively Z-alcohols 10 (Scheme 2). The original method was aiming at the allylation products $\mathbf{1 0}$ using excess boronates $( \pm)-\mathbf{4}$, while the fate of the unreacted boronates was ignored, partly because they generally tend to decompose under the standard basic work up conditions. ${ }^{[10 \mathrm{~b}]}$ However, the Epin-derived boronates turned out to remain intact and could be readily separated from $\mathbf{1 0}$ by chromatography on silica. ${ }^{[11]}$ Therefore, we reasoned that the method could be recast into obtaining highly enantioenriched boronates 4 by resolving their racemic mixtures. The initial trials produced encouraging results. With a 2:1 ratio of boronate $( \pm)-\mathbf{4 a}$ to benzaldehyde $8 \mathrm{a}$ using $5 \mathrm{~mol} \%$ of (R)-TRIP at $-40^{\circ} \mathrm{C}$, allylboronate $(S)-4$ a was obtained in $45 \%$ yield (or $91 \%$ with respect to the maximum expected amount) and in $97 \%$ ee; the alcohol (Z)-10aa formed in the same process was isolated in $47 \%$ yield and $75 \%$ ee (ZIE 5:1). In the absence of a direct procedure, the enantiopurity of the isolated boronate was established by reacting it with benzaldehyde and measuring ee of the resulting alcohols (S)-10aa. ${ }^{[7 b]}$ We were able to further boost the enantiomeric purity of the boronate to $99 \%$ ee by slightly increasing the amount of benzaldehyde to 1.05 equiv. ${ }^{[12]}$ These conditions were set as optimal. Furthermore, for the resolution of $\mathbf{4 a}$, the catalysts loading can be reduced to $1 \mathrm{~mol} \%$ without affecting the efficiency of the reaction ( $89 \%$ yield, $99 \%$ ee).<smiles>[R]C=CC([R])Br</smiles>

$( \pm)-4 a-4 e$

2.0 equiv<smiles>O=Cc1ccccc1</smiles>

1.05 equiv

$8 a$<smiles>O=P(O)(Oc1ccccc1)Oc1c(Br)cc2ccccc2c1-c1cc2ccccc2cc1Br</smiles>
$\mathrm{Ar}=1,3,5-(i \mathrm{Pr})_{3}-\mathrm{C}_{6} \mathrm{H}_{2}$ 9 (R)-TRIP (1-5 mol\%) Toluene, $-40^{\circ} \mathrm{C}, 22-48 \mathrm{~h}$<smiles>[R7]C=CC([R])[Bi]</smiles>

$(S)-4 a-4 e$

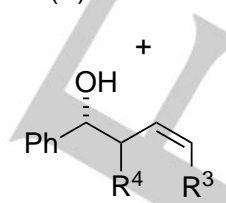

$(R, Z)-10 \mathrm{aa}-10 \mathrm{ae}$<smiles>C=CC(C)Br</smiles>

(S)-4a

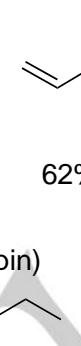

(S)-4d

$54 \%$, ee $99 \%$

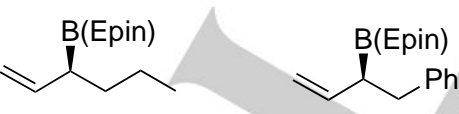

(S) $-\mathbf{4 b}$

$62 \%$, ee $94 \%$
(S) $-4 \mathrm{c}$ $70 \%$, ee $98 \%$

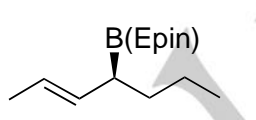

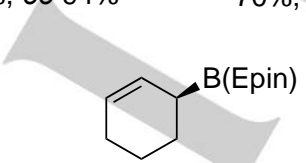

(S) $-4 \mathrm{e}$

$62 \%$, ee $96 \%$
Scheme 2. Kinetic resolution of racemic secondary allylboronates. The yields of boronates $\mathbf{4}$ are given with respect to the maximum expected amount in the resolution protocol.

Next, we examined kinetic resolution of a range of secondary boronates $\mathbf{4 b - 4 e}$, where $\mathbf{4 b}$ and $\mathbf{4 c}$ are higher homologues of $\mathbf{4 a}$, whereas substrates $\mathbf{4 d}$ and $\mathbf{4 e}$ feature $E$ and $Z$ internal double bond, respectively. All the substrates were readily synthesized in a 1- or 2-step sequence by known methods. ${ }^{[13]}$ The additional steric bias brought by the substituents affected the reactivity of these boronates compared to the parent $\mathbf{4 a}$, therefore the catalyst loading of $5 \mathrm{~mol} \%$ had to be employed. In all cases, the kinetic resolution proceeded efficiently to furnish highly enantioenriched boronates $\mathbf{4 b}-\mathbf{4 e}$ (Scheme 2). It is worth mentioning the respectable enantiopurity of the alcohols $(R)-\mathbf{1 0}$ formed during the resolution of the boronates: $(R)-\mathbf{1 0 a b}-84 \%$ ee),$(R)-\mathbf{1 0 a c}-70 \%$ ee, $(R)-10 a e-84 \%$ ee. ${ }^{[14]}$

With the set of enantioenriched boronates in hand, we embarked on their application in the synthesis of chiral amines. In contrast to the well-understood asymmetric allylation of aldehydes, proceeding via highly organised chair-like transition state, the related allylation of imines is more multifaceted and hence more challenging. ${ }^{[2 b]}$ Substitution on the imine nitrogen provides an excellent opportunity to tune electrophilicity of the $\mathrm{C}=\mathrm{N}$ bond, however that also brings additional elements of complexity. These, among others, include $E / Z$ isomerism about the $\mathrm{C}=\mathrm{N}$ bond and a possible imine-enamine tautomerism in the case of enolisable imines. Furthermore, the steric constraints imposed by the $R^{2}$ substituent on the nitrogen in $\mathbf{2}$ and forcing it into a pseudo-axial position in the cyclic transition state (see TS A and B, Scheme 1b) often lead to different stereochemical outcome to what would be normally observed with aldehydes. ${ }^{[15]}$ Taking into consideration that the steric arrangement of the transition state of $\mathrm{NH}$ imines should resemble that of aldehydes, they would represent an ideal choice. However, due to their poor stability, the $\mathrm{NH}$ aldimines are usually synthesized and used in situ. In this work, two approaches were explored (Scheme 3).

a) allylation of $\mathrm{N}$-trimethylsilylimine

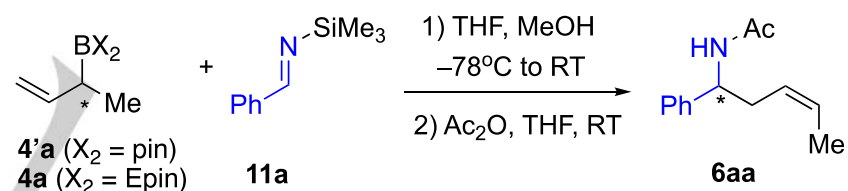

b) aminoallylation of aldehydes

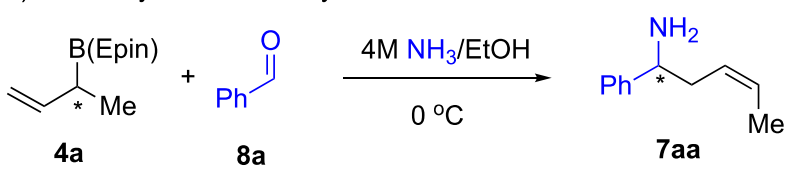

Scheme 3. Optimization of crotylation of imines with 4

First, the $\mathrm{N}$-trimethylsilylimine 11a was assessed (Scheme 3a). The TMS protection is removed during the reaction to expose the $\mathrm{NH}$ group. ${ }^{[4 a, 4 b, 16]}$ In preliminary trials that were conducted using racemic 4'a and $\mathbf{4 a}$, the Bpin boronate 4'a afforded Z-6aa in $70 \%$ and $5: 1 \mathrm{dr}$. The selectivity towards $Z$ isomer improved to $10: 1$ when 4a was employed (82\% yield). With the enantioenriched $(S)-4 a(98 \% e e)$, a complete transfer of chirality was observed, in agreement with previous reports on the reactions of homochiral secondary allylboronates. ${ }^{[4 a, 4 b, 4 d]}$ However, synthesis of pure N-TMS imines requires purification by distillation, which narrows the substrate scope. ${ }^{[16]}$ Alternatively, they can be made and used in situ at low temperature, which adds complexity to the synthetic protocol. 
Therefore, our attention turned to the aminoallylation of aldehydes in a solution of ammonia in ethanol (Scheme 3b, $\mathbf{4 a} \rightarrow$ 7aa). The racemic variant of the method was reported by Kobayashi, ${ }^{[17]}$ who employed primary pinacol-derived allyl- and crotylboronates. It is noteworthy that primary boronates decorated with a chiral auxiliary in the diol moiety failed to induce practical enantioselectivity. ${ }^{[17 a]}$ Later, two examples of the use of chiral boron reagents was reported by Morken. ${ }^{[4 b]}$ In our initial trial, imine 2a was formed by stirring benzaldehyde in $4 \mathrm{M}$ ammonia in ethanol ( $1 \mathrm{~mL}, \mathrm{ca} .8$ equiv) for $0.5 \mathrm{~h}$ at $-10^{\circ} \mathrm{C}$, followed by addition of racemic boronate $4 \mathrm{a}$ ( 1.2 equiv). After $18 \mathrm{~h}$, the amine $7 \mathrm{aa}$ was isolated in $83 \%$ yield (Z/E 8:1). A similar result was obtained at $0^{\circ} \mathrm{C}$ (yield $78 \%, Z / E$ 8:1). Other solvents, such as $\mathrm{MeOH}, \mathrm{PrOH}$ $t \mathrm{BuOH}$ and THF proved inferior. The conditions shown in Scheme $3 \mathrm{~b}$ were taken as optimal for investigating the reaction scope using resolved $(S)$-4a (Table 1)

Table 1. Scope in the allylation of imines with enantioenriched $(S)-\mathbf{4 a} .^{[a]}$

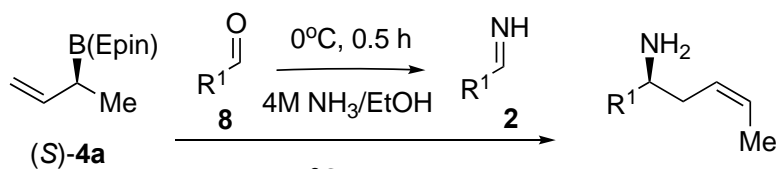

1.2 equiv $0^{\circ} \mathrm{C}, 18 \mathrm{~h}$
Allylation of 2a with (S)-4a gave (S)-7aa in $97 \%$ ee and with the $Z / E$ ratio (8:1), analogous to the racemic reaction (entry 1 ). A higher Z-selectivity was observed at $-40^{\circ} \mathrm{C}(24: 1)$, though at the expense of lower product yield, even after 4 days (entry 2 ). With aromatic aldehydes $\mathbf{8 b} \mathbf{8} \mathbf{8 g}$ (entries 3-9), the reaction followed the same trend irrespective of the nature of substituents with a highly efficient chirality transfer. Note a slight improvement in the Z/E ratio for $7 \mathrm{da}$ at $-10^{\circ} \mathrm{C}$ (cf. entries 5 and 6 ). For a more sterically hindered ortho-substituted aldehyde $\mathbf{8 h}$, the reaction had to be carried out at RT, which also affected the enantioselectivity of the process (entry 10). A slight erosion of enantioselectivity was also observed for cinnamaldehyde $\mathbf{8} \mathbf{i}$ and aliphatic aldehydes $\mathbf{8 j - 8}$, though enantiopurity of the products still remained high (entries 11-14). No product was formed with 2 -furylaldehyde $8 \mathrm{~m}$, which was probably due to a very slow formation of the respective imine under the reaction conditions (entry 15).

Next, other resolved allylboronates $\mathbf{4 b} \mathbf{b}-\mathbf{4 e}$ were examined in the aminoallylation reaction (Scheme 4 ). Boronates (S)-4b and (S)-4c with an extended alkyl chain exhibited somewhat slower reaction rates, possibly due to the increased steric size of the substituent at the chiral center. However, this had a positive influence on the $Z / E$ ratio (up to $27: 1$ for $7 a c$ ). Boronates $(S)-4 d$ and $(S)-4 \mathrm{e}$ with $E$ and $Z$ internal double bond produced, respectively, anti-7ad and syn-7ae, which suggests that the reaction proceeded through the chair-like transition states resembling those for the aldehydes. Enantiopurity of the products closely matches the enantiopurity of the starting boronates reflecting an efficient transfer of chirality in the process.

\begin{tabular}{|c|c|c|c|c|c|c|}
\hline & $8, R^{1}$ & 7 & Yield [\%] & $7, Z / E$ & $7, e e[\%]$ & $\begin{array}{l}\text { respectively, anti-7ad and syn-7ae, which suggests that the } \\
\text { reaction proceeded through the chair-like transition states }\end{array}$ \\
\hline 1 & $8 \mathbf{a}, \mathrm{Ph}$ & $7 a a$ & 76 & $8: 1$ & 97 & resembling those for the aldehydes. Enantiopurity of the products \\
\hline $2^{[b]}$ & $8 \mathbf{a}, \mathrm{Ph}$ & $7 a a$ & 29 & $24: 1$ & n.d. & reflecting an efficient transfer of chirality in the process. \\
\hline
\end{tabular}

\begin{tabular}{|c|c|c|c|c|c|}
\hline 3 & $8 \mathbf{b}, 4-\mathrm{MeC}_{6} \mathrm{H}_{4}$ & $7 \mathrm{ba}$ & 72 & $10: 1$ & 99 \\
\hline 4 & $8 c, 4-\mathrm{BrC}_{6} \mathrm{H}_{4}$ & 7ca & 65 & $8: 1$ & 98 \\
\hline 5 & $8 \mathrm{~d}, 4-\mathrm{ClC}_{6} \mathrm{H}_{4}$ & 7da & 75 & $9: 1$ & 99 \\
\hline $6^{[c]}$ & $8 d, 4-\mathrm{ClC}_{6} \mathrm{H}_{4}$ & 7da & 57 & $10: 1$ & 99 \\
\hline $7^{[\mathrm{d}]}$ & $8 e, 4-\mathrm{FC}_{6} \mathrm{H}_{4}$ & 7ea & 53 & $7: 1$ & 99 \\
\hline 8 & 8f, 4- $\mathrm{MeOC}_{6} \mathrm{H}_{4}$ & $7 \mathrm{fa}$ & 63 & $9: 1$ & 98 \\
\hline 9 & $8 \mathbf{g}, 3-\mathrm{MeOC}_{6} \mathrm{H}_{4}$ & $7 g a$ & 78 & $9: 1$ & 98 \\
\hline $10^{[\mathrm{e}]}$ & $8 \mathrm{~h}, 2-\mathrm{MeOC}_{6} \mathrm{H}_{4}$ & 7ha & 61 & $10: 1$ & 85 \\
\hline 11 & $8 \mathrm{i}, \mathrm{PhCH}=\mathrm{CH}$ & $7 \mathbf{i a}$ & 72 & & 94 \\
\hline 12 & $8 \mathbf{j}, \mathrm{PhCH}_{2} \mathrm{CH}_{2}$ & 7ja & 59 & $8: 1$ & $93^{[\mathrm{f}]}$ \\
\hline 13 & $\mathbf{8 k}, n-\mathrm{C}_{7} \mathrm{H}_{15}$ & 7ka & 76 & $8: 1$ & $96^{[f]}$ \\
\hline $14^{[\mathrm{e}]}$ & $8 \mathrm{I}, c-\mathrm{C}_{6} \mathrm{H}_{11}$ & 7la & 34 & $8: 1$ & 91 \\
\hline $15^{[e]}$ & 8m, 2-Furyl & $7 \mathrm{ma}$ & $<10$ & n.d. & n.d. \\
\hline
\end{tabular}

[a] The reactions were carried out at $0.1-0.2 \mathrm{mmol}$ scale at $0^{\circ} \mathrm{C}$ unless stated otherwise; yields of the isolated compounds are given; the Z/E ratios were determined by ${ }^{1} \mathrm{H}$ or ${ }^{19} \mathrm{~F}$ NMR of a crude reaction mixture; ee of the products was determined by chiral HPLC analysis; n.d. - not determined. [b] At $-40^{\circ} \mathrm{C}$, reaction time $96 \mathrm{~h}$. [c] At $-10^{\circ} \mathrm{C}$. [d] The absolute configuration was confirmed by X-ray analysis of the corresponding acetamide (see Supporting Information for details). [e] At RT. [f] The product was $(R)$-configured due to the change in the preference of the substituents in the Cahn-Ingold-Prelog system.

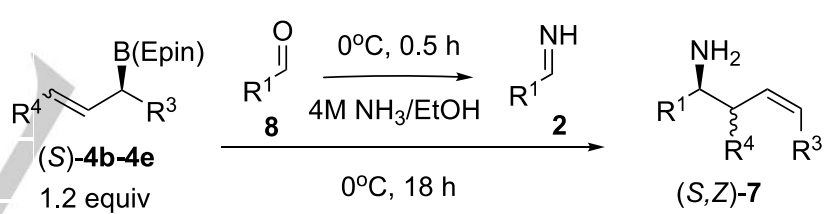

$(S, Z)-7$<smiles>CC(C)C/C=C\C[C@H](N)c1ccccc1</smiles>

(S)-7ab

$62 \%$, ee $92 \%$ Z/E 10:1<smiles>NC(C/C=C\Br)c1ccccc1</smiles>

$(S)-7$ ac

$62 \%$, ee $97 \%$ Z/E 27:1<smiles>CC(C)/C=C/[C@H](N)/C=C\c1ccccc1</smiles>

$(S)-7 \mathrm{ib}$ $59 \%$, ee $95 \%$ ZIE 15:1<smiles>CC(C)/C=C\C(C)C(N)c1ccccc1</smiles>

(S)-7ad

$71 \%$, ee $99 \%$ Z/E 11:1<smiles>N[C@@H](C/C=C\Cc1ccccc1)CCc1ccccc1</smiles>

$(R)-7 \mathbf{j b}$ ZIE 10:1

Scheme 4. Allylation of imines with enantioenriched boronates (S)-4b-4e.

In conclusion, we have developed an expedient practical method for obtaining highly enantioenriched secondary allylboronates (up to $99 \%$ ee) by kinetic resolution of their racemic mixtures employing chiral phosphoric acid TRIP. The use of the new Epin fragment at boron enhanced stability of the allyl boronates towards silica thus simplifying their purification and 
handling. The resolved boronates were employed for the efficient stereoselective synthesis of chiral homoallylic amines with $Z$ configured internal double bond by reacting with imines formed in situ from aldehydes and ethanolic ammonia. The salient features of the process are (i) excellent chirality transfer and (ii) high stereoselectivity benefiting from the increased steric radius of the Epin fragment. The work is currently underway in our laboratories on other synthetic applications of the resolved enantioenriched allylboronates.

\section{Acknowledgements}

We thank the Leverhulme Trust for the Research grant RGP2015-351. Spanish MINECO (FEDER-CTQ2017-83633-P and FPI-BES-2012-051856 fellowship to L. V.) and Basque Government (IT908-16), are also gratefully acknowledged. We thank Prof. Dr. V. K. Aggarwal and J. Bateman (University of Bristol) for their kind advice and assistance in synthesizing $\mathbf{4 d}$.

Keywords: asymmetric synthesis $•$ allylation $\bullet$ amines $\bullet$ kinetic resolution • stereoselectivity

[1] a) D. C. Blakemore, L. Castro, I. Churcher, D. C, Rees, A. W. Thomas, D. W. Wilson, A. Wood, Nat. Chem. 2018, 10, 383-394; b) T. Nugent, in Process Chemistry in the Pharmaceutical Industry, Volume 2, CRC Press, 2007, pp. 137-156.

[2] For overviews, see: a) B. Eftekhari-Sis, M. Zirak, Chem. Rev. 2017, 117, 8326-8419; b) M. Yus, J. C. González-Gómez, F. Foubelo, Chem. Rev. 2011, 111, 7774-7854; c) T. R. Ramadhar, R. A. Batey, Synthesis 2011 1321-1346. For the most recent examples, see: d) S. Gandhi, B. List, Angew. Chem. Int. Ed. 2013, 52, 2573-2576; e) K. Yeung, R. E. Ruscoe, J. Rae, A. P. Pulis, D. J. Procter, Angew. Chem. Int. Ed. 2016, 55 , 11912-11916; f) J. Rae, K. Yeung, J. J. W. McDouall, D. J. Procter, Angew. Chem. Int. Ed. 2016, 55, 1102-1107; g) M. Coffinet, J.-B. Behr, F. Jaroschik, D. Harakat, J.-L. Vasse, Org. Lett. 2017, 19, 6728-6731.

[3] a) E. M. Vieira, M. L. Snapper, A. H. Hoveyda, J. Am. Chem. Soc. 2011 133, 3332-3335; b) Y. Jiang, S. E. Schaus, Angew. Chem. Int. Ed. 2017 56, 1544-1548; c) D. L. Silverio, S. Torker, T. Pilyugina, E. M. Vieira, M. L. Snapper, F. Haeffner, A. H. Hoveyda, Nature 2013, 494, 216-221; d) S. Itsuno, K. Watanabe, A. A. El-Shehawy, Adv. Synth. Catal. 2001, 343, 89-94; e) S. Lou, P. N. Moquist, S. E. Schaus, J. Am. Chem. Soc. 2007 129, 15398-15404; f) R. Wada, T. Shibuguchi, S. Makino, K. Oisaki, M. Kanai, M. Shibasaki, J. Am. Chem. Soc. 2006, 128, 7687-7691; g) R Alam, C. Diner, S. Jonker, L. Eriksson, K. J. Szabó, Angew. Chem. Int. Ed. 2016, 55, 14417-14421.

[4] a) J. L.-Y. Chen, V. K. Aggarwal, Angew. Chem. Int. Ed. 2014, 53, 10992-10996; b) J. D. Sieber, J. P. Morken, J. Am. Chem. Soc. 2006 128, 74-75; c) J. I. Martínez, J. J. Smith, H. B. Hepburn, H. W. Lam, Angew. Chem. Int. Ed. 2016, 55, 1108-1112; d) C. Allais, W. R. Roush, Org. Lett. 2017, 19, 2646-2649.

[5] Y. Yamamoto, T. Komatsu, K. Maruyama, J. Org. Chem. 1985, 50, 31153121.

[6] For the recent overviews on the synthesis of $\alpha$-chiral non-racemic allylboronates, see: a) C. Diner, K. J. Szabó, J. Am. Chem. Soc. 2017, 139, 2-14; b) B. S. L. Collins, C. M. Wilson, E. L. Myers, V. K. Aggarwal, Angew. Chem. Int. Ed. 2017, 56, 11700-11733.

[7] a) R. W. Hoffmann, B. Landmann, Angew. Chem. Int. Ed. 1984, 23, 437438; b) R. W. Hoffmann, Pure Appl. Chem. 1988, 60, 123-130; c) J. Pietruszka, N. Schöne, Angew. Chem. Int. Ed. 2003, 42, 5638-5641; d) E. Fernández, J. Pietruszka, Synlett 2009, 1474-1476; e) M. Brauns, F Muller, D. Gülden, D. Böse, W. Frey, M. Breugst, J. Pietruszka, Angew. Chem. Int. Ed. 2016, 55, 1548-1552.
[8] a) M. Althaus, A. Mahmood, J. R. Suárez, S. P. Thomas, V. K. Aggarwal, J. Am. Chem. Soc. 2010, 132, 4025-4028; b) A. P. Pulis, V. K. Aggarwal, J. Am. Chem. Soc. 2012, 134, 7570-7574.

[9] a) L. Carosi, D. G. Hall, Angew. Chem. Int. Ed. 2007, 46, 5913-5915; b) H. Ito, S. Ito, Y. Sasaki, K. Matsuura, M. Sawamura, J. Am. Chem. Soc. 2007, 129, 14856-14857; c) S. Lessard, F. Peng, D. G. Hall, J. Am. Chem. Soc. 2009, 131, 9612-9613; d) A. Guzman-Martinez, A. H. Hoveyda, J. Am. Chem. Soc. 2010, 132, 10634-10637; e) H. Ito, S. Kunii, M. Sawamura, Nat. Chem. 2010, 2, 972-976; f) J. K. Park, H. H. Lackey, B. A. Ondrusek, D. T. McQuade, J. Am. Chem. Soc. 2011, 133, 2410 2413; g) L. T. Kliman, S. N. Mlynarski, G. E. Ferris, J. P. Morken, Angew. Chem. Int. Ed. 2012, 51, 521-524; h) Y. Luo, I. D. Roy, A. G. E. Madec, H. W. Lam, Angew. Chem. Int. Ed. 2014, 53, 4186-4190; i) E. Yamamoto, Y. Takenouchi, T. Ozaki, T. Miya, H. Ito, J. Am. Chem. Soc. 2014, 136, 16515-16521; j) B. Potter, A. A. Szymaniak, E. K. Edelstein, J. P. Morken, J. Am. Chem. Soc. 2014, 136, 17918-17921; k) Q. Zhou, H. D. Srinivas, S. Zhang, M. P. Watson, J. Am. Chem. Soc. 2016, 138, 11989-11995; I) E. K. Edelstein, S. Namirembe, J. P. Morken, J. Am. Chem. Soc. 2017, 139, 5027-5030; m) R. Kojima, S. Akiyama, H. Ito, Angew. Chem. Int. Ed. 2018, 57, 7196-7199.

[10] a) C. A. Incerti-Pradillos, M. A. Kabeshov, A. V. Malkov, Angew. Chem. Int. Ed. 2013, 52, 5338-5341. For a related propargylation reaction, see b) A. S. Tsai, M. Chen M, W. R. Roush, Org. Lett. 2013, 15, 1568-1571. The resolved boronates have not been isolated.

[11] This contrasts sharply with the boronates decorated with the pinaco 'helmet' which usually needs to be purified on silica within 10 min to prevent degradation. In fact, Epin-derived allyl boronates did not show any degradation or erosion of enantiomeric purity even after being left on silica overnight.

[12] Racemic allyl boronates $\mathbf{4 a}$ and $\mathbf{4 b}$ may contain small quantity of the linear isomer (ca. 2-5\%). Excess of benzaldehyde during the kinetic resolution allows to remove the latter as it reacts much faster compared to the branched isomer.

[13] Substrate were synthesized following literature protocols. For $\mathbf{4 a - 4 b}$, see ref $10 \mathrm{a}$ or a) J. W. Clary, T. J. Rettenmaier, R. Snelling, W. Bryks, J. Banwell, W. T. Wipke, B. Singaram, J. Org. Chem. 2011, 76, 9602-9610. For 4c, see b) R. P. Sonawane, V. Jheengut, C. Rabalakos, R. LaroucheGauthier, H. K. Scott, V. K. Aggarwal, Angew. Chem. Int. Ed. 2011, 50, 3760-3763. For 4d, see ref 8a. For 4e, see c) C.-T. Yang, Z.-Q. Zhang, H. Tajuddin, C.-C. Wu, J. Liang, J.-H. Liu, Y. Fu, M. Czyzewska, P. G Steel, T. B. Marder, L. Liu, Angew. Chem. Int. Ed. 2012, 51, 528-532.

[14] The Epin diol can be efficiently recovered after the reaction (both kinetic resolution and imine allylation) and reused in the synthesis of the starting allyl boronates. (See Supporting Information for details)

[15] a) Y. Yamamoto, N. Asao, Chem. Rev. 1993, 93, 2207-2293; b) R. Alam, A. Das, G. Huang, L. Eriksson, F. Himo, K. J. Szabó, Chem. Sci. 2014 5, 2732-2738.

[16] E. W. Colvin, D. McGarry, M. J. Nugent, Tetrahedron 1988, 44, 41574172.

[17] a) M. Sugiura, K. Hirano, S. Kobayashi, J. Am. Chem. Soc. 2004, 126, 7182-7183; b) S. Kobayashi, K. Hirano, M. Sugiura, Chem. Commun. 2005, 104-106. 


\section{Entry for the Table of Contents}

\section{COMMUNICATION}

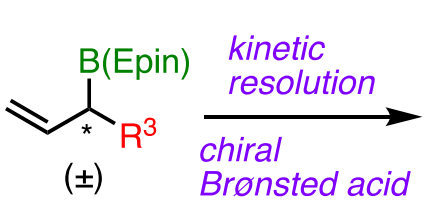

Epin $=1,1,2,2-$

tetraethyl-1,2-ethanediol

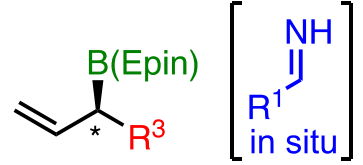

ee $94-99 \%$

5 examples<smiles>[R]C=CC[C@H]([R])N</smiles>

up to $99 \%$ ee Z/E up to $27: 1$

18 examples

Size matters: increased hydrolytic stability of allylboronates with Epin fragment enabled facile kinetic resolution of their racemic mixture followed by stereoselective allylation of unprotected imines

Laura Villar, Nikolai V. Orlov, Nikolay S. Kondratyev, Uxue Uria, Jose L. Vicario, * and Andrei V. Malkov*

\section{Page No. - Page No.}

Kinetic resolution of secondary allylboronates and their application in the synthesis of homoallylic amines 